\title{
Current Evidence on Atypical Odontalgia: Diagnosis and Clinical Management
}

\author{
Yoshihiro Abiko, ${ }^{1}$ Hirofumi Matsuoka, ${ }^{2}$ Itsuo Chiba, ${ }^{2}$ and Akira Toyofuku ${ }^{3}$ \\ ${ }^{1}$ Division of Oral Medicine and Pathology, School of Dentistry, Health Sciences University of Hokkaido, 1757 Kanazawa, \\ Ishikari-Tobetsu, Hokkaido 061-0293, Japan \\ ${ }^{2}$ Division of Disease Control \& Molecular Epidemiology, School of Dentistry, Health Sciences University of Hokkaido, \\ 1757 Kanazawa, Ishikari-Tobetsu, Hokkaido 061-0293, Japan \\ ${ }^{3}$ Department of Psychosomatic Dentistry, Faculty of Dentistry, Graduate School of Medical and Dental Science, \\ Tokyo Medical and Dental University, Tokyo 113-8510, Japan
}

Correspondence should be addressed to Yoshihiro Abiko, yoshi-ab@hoku-iryo-u.ac.jp

Received 18 January 2012; Accepted 29 May 2012

Academic Editor: Toshiya Koitabashi

Copyright ( 2012 Yoshihiro Abiko et al. This is an open access article distributed under the Creative Commons Attribution License, which permits unrestricted use, distribution, and reproduction in any medium, provided the original work is properly cited.

Patients with atypical odontalgia (AO) complain of medically unexplained toothache. No evidence-based diagnostic criteria or treatment guidelines are yet available. The present paper addresses seven clinical questions about AO based on current knowledge in the literature and discusses diagnostic criteria and guidelines for treatment and management. The questions are (i) What is the prevalence of $\mathrm{AO}$ in the community? (ii) What psychological problems are experienced by patients with AO? (iii) Are there any comorbidities of AO? (iv) Is local anesthesia effective for the relief of pain in AO? (v) Are there any characteristic symptoms of AO other than spontaneous pain? (vi) Are antidepressants effective for treatment of AO? (vii) Are anticonvulsants effective for treatment of $\mathrm{AO}$ ? Our literature search provided answers for these questions; however, there is insufficient evidence-based data to establish guidelines for the diagnosis and treatment of AO. Overall, some diagnostic criteria for neuropathic pain and persistent dentoalveolar pain disorder may be applied to AO patients. The patient's psychogenic background should always be considered in the treatment and/or management of AO. The clinicians may need to treat AO patients using Patient-Oriented Evidence that Matters approach.

\section{Introduction}

Patients with atypical odontalgia $(\mathrm{AO})$ complain of medically unexplained toothache. Symptoms include pain without any pathological changes and/or stronger pain than would be expected from the clinical findings. AO is a subgroup of persistent idiopathic facial pain disorder as defined by the International Headache Society [1]. Any dental procedures including scaling, restorative treatment, and endodontic treatment pose potential risk of AO. In many cases, the persistent nature of the pain prompts dentists to treat the teeth in the absence of any pathological findings. The treatment often exacerbates the pain instead of relieving it. Dentists usually consider a diagnosis of AO only after the failure of invasive treatment. Although it is crucial to establish diagnostic criteria for $\mathrm{AO}$, the evidencebased literature to date has been insufficient to make this possible.

Several clinical management methods for $\mathrm{AO}$ have been reported [2-11]. The pathophysiological mechanism of AO may provide useful information for effective management. Possible pathophysiological mechanisms for AO include those with neuropathic, vascular, and psychogenic origins. Since the clinical course of $\mathrm{AO}$ varies among patients, and each case may stem from a different origin, a universal treatment method may not be effective for all AO patients, and it may be difficult to establish an evidence base for clinical management. 
We formulated seven questions based on our clinical experience in the Japanese Society of Psychosomatic Dentistry. The questions are

(i) What is the prevalence of AO in the community?

(ii) What psychological problems are experienced by patients with $\mathrm{AO}$ ?

(iii) Are there any comorbidities of $\mathrm{AO}$ ?

(iv) Is local anesthesia effective for the relief of pain in $\mathrm{AO}$ ?

(v) Are there any characteristic symptoms of $\mathrm{AO}$ other than spontaneous pain?

(vi) Are antidepressants effective for treatment of AO?

(vii) Are anticonvulsants effective for treatment of $\mathrm{AO}$ ?

These questions will be reviewed based on current knowledge in the literature, and diagnostic criteria and guidelines for treatment and management will be discussed.

\section{What Is the Prevalence of AO in the Community?}

AO was found in $2.1 \%$ of a population of 3000 at the University of Southern California Orofacial Pain and Oral Medicine Center [12]. Other studies suggest that AO occurs in $3-6 \%$ of patients undergoing endodontic treatment [2, 13-17]. Polycarpou et al. [18] examined 175 patients at the Eastman Dental Hospital, a secondary healthcare facility, and found the prevalence of persistent pain after successful root canal treatments was $12 \%$. They determined that significant risk factors leading to the development of chronic pain after endodontic treatment were the presence and duration of preoperative pain from the tooth, tenderness to percussion of the tooth preoperatively, female gender, previous painful treatment in the orofacial region, previous chronic pain problems, and whether surgical treatment was received. It is generally agreed that $\mathrm{AO}$ occurs more frequently in females than in males; $80-90 \%$ of all cases are female [7, 19-23]. Complaints were predominantly reported in the upper jaw (ratio $8: 2$ ) with the majority in the molar region (ratio $5: 3$ ) [20]. List et al. [24] reported in a study of 46 cases of AO that $56 \%$ of patients complained of pain in the upper jaw, compared with $45 \%$ in the lower jaw (one patient had pain in both jaws). These frequencies are useful for diagnosing $\mathrm{AO}$ after successful root canal treatment.

\section{What Psychological Problems Are Experienced by Patients with AO?}

Psychogenic pain is caused, increased, or prolonged by mental, emotional, or behavioral factors [25]. In addition to psychogenic pain, other pathophysiological mechanisms including neuropathic and vascular abnormalities have been linked with AO. Since the pain debut of $83 \%$ of AO patients was related to an invasive dental or surgical procedure [26], AO could be attributed to neuropathic pain caused by deafferentation [27-29]. However, pain in AO can also be spontaneous with no history of invasive dental or surgical procedures. Vascular pain has been proposed as a mechanism for $\mathrm{AO}$, since $\mathrm{AO}$ patients occasionally suffer from migraine possibly caused by vascular events [30]. No scientific evidence has supported this hypothesis thus far [1, 31]. AO patients usually experience associated psychological problems such as depression, somatoform pain disorder, anxiety, demoralization, introversion, or hypochondriacal psychosis $[6,8,21,32-40]$. AO patients may have a history of depression $(66 \%)$ or depressive symptom $(41 \%)$ [21, 41$]$. List et al. [26] examined 46 patients with $\mathrm{AO}$ and found significantly higher scores for depression and somatization in the $\mathrm{AO}$ group than the control group. Baad-Hansen et al. [42] found that mean depression and somatization scores were moderate to high in 46 patients with AO. These studies support a strong correlation between $\mathrm{AO}$ and psychological conditions. These psychological problems, however, may not reflect psychiatric diagnoses of AO. Takenoshita et al. [43] investigated $37 \mathrm{AO}$ patients referred from psychiatric facilities to dental clinics and found that $33.3 \%$ of the patients had no specific psychiatric diagnosis. It is not known whether AO patients with no specific psychiatric conditions experience neuropathic and/or vascular pain. The psychiatric or psychological approach is generally effective but may not be absolutely essential for $\mathrm{AO}$ patients.

There is some argument as to whether psychological problems are the primary or secondary cause of AO [15, 42]. Graff-Radford [44] suggested that depression was not the cause of AO, and Brooke and Merskey [45] hypothesized that depression was not the sole cause of AO. These reports suggest that psychological factors are not significant in the genesis of $\mathrm{AO}$ [15]. Whether psychological problems are primary or secondary causes of $\mathrm{AO}$, the psychological background of the patient should always be considered, given the high incidence of psychological problems in $\mathrm{AO}$ patients.

\section{Are There Any Comorbidities of AO?}

AO may share pain mechanisms with other chronic orofacial pain conditions, such as atypical facial pain and temporomandibular disorder (TMD). Baad-Hansen et al. [42] examined $46 \mathrm{AO}$ patients and showed that episodic tension-type headache (TTH), chronic TTH, and myofascial temporomandibular disorder occurred in $46 \%, 18 \%$, and $50 \%$ of AO patients, respectively. Other researchers reported that TMD pain, TTH, and widespread pain were significantly more common among $\mathrm{AO}$ patients than controls [26]. In addition to being linked with TMD or TTH, AO has been reported in patients with burning mouth syndrome (BMS) $[11,46-48]$. However, no statistical data to date has established the frequency of the comorbidity of AO with BMS. TMD should be considered as a comorbid disorder for AO.

\section{Is Local Anesthesia Effective for the Relief of Pain in AO?}

Several investigators have studied the use of local anesthesia to relieve the pain of OA. Vickers et al. [10] reported 
a significant reduction in pain in a group of $\mathrm{AO}$ patients treated with local anesthesia. A randomized controlled trial undertaken by List et al. [5] corroborated the evidence of this paper. List et al. [5] evaluated the analgesic effect of local anesthesia (lidocaine) in a randomized controlled trial on 35 consecutive AO patients. They concluded that $\mathrm{AO}$ patients experienced significant, but not complete, pain relief from administration of local anesthetics compared with placebo. The pain relief was transient and was only at 15-120 min following the administration of the local anesthetics. In contrast, Graff-Radford and Solberg [49] found no significant difference in pain relief in AO patients after administration of local anaesthetic, although patients with nociceptive pain significantly improved. Two other uncontrolled studies showed similar findings $[19,21]$. The clinical course of $\mathrm{AO}$ patients varies, and the effectiveness of local anesthesia may depend on the type of pathophysiological mechanisms of AO. Lidocaine patches were found to be clearly effective in reducing ongoing pain and allodynia in peripheral neuropathic pain syndrome [50]. Local anesthesia may transiently relieve pain in $\mathrm{AO}$ patients whose pain stems from neuropathic sources. Further investigations are needed to clarify this hypothesis.

\section{Are There Any Characteristic Symptoms of AO Other Than Spontaneous Pain?}

The persistent pain in $\mathrm{AO}$ can be altered by various stimuli. The sensations of $10 \mathrm{AO}$ patients were compared with 10 matched healthy controls. The AO patients showed increased sensitivity to capsaicin and heat pain, but no significant differences in cold and mechanical sensitivity [13]. A study by Zagury et al. [51] comparing 21 AO patients with 18 controls found that the duration of pain sensation on cold application was significantly longer in $\mathrm{AO}$ patients, although the level of pain to cold stimulus was not statistically different between the $\mathrm{AO}$ and control group. List et al. [24] observed significant abnormalities in intraoral somatosensory function in $\mathrm{AO}$ patients, which may reflect peripheral and central sensitization of trigeminal pathways.

\section{Are Antidepressants Effective for Treatment of AO?}

A meta-analysis of available data revealed that in patients diagnosed with psychogenic pain or somatoform pain disorder, antidepressant treatment resulted in a reduction in pain that was significantly greater than that of placebo [52]. Tricyclic antidepressants (TCAs) are the standard treatment choice for psychogenic pain or somatoform pain disorder. In the management of AO, TCAs have usually been prescribed alone or in combination with phenothiazines $[2-4,6-9,11$, 53, 54] (Figure 1). Adverse effects should be considered when prescribing both TCAs and phenothiazines. Phenothiazines have been linked with potentially irreversible adverse effects in the nervous system causing tardive dyskinesia. A literature review by Baad-Hansen et al. [42] noted that there is a need for a high-quality randomized controlled trial in $\mathrm{AO}$

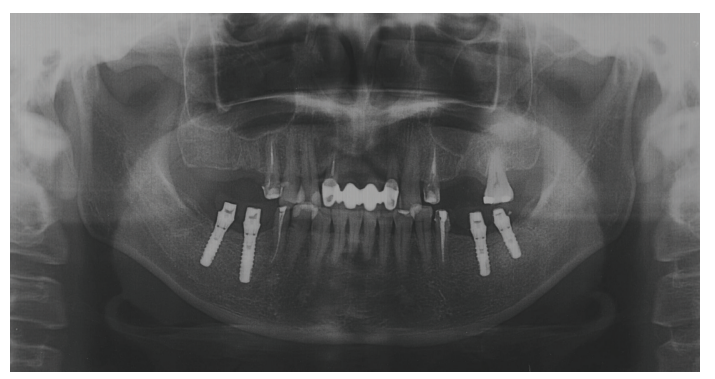

FIGURE 1: Panoramic radiograph shows a case of atypical odontalgia causing in a 57-year-old woman. The woman complained of toothache in the bilateral upper molars after the replacement of dental implant into the lower jaws. The root canal treatments of upper molars were performed, and the upper molars were finally extracted, since her pain was not relived by any treatments. A prescription of $40 \mathrm{mg}$ per a day of amitriptyline decreased symptoms in the patient.

patients to evaluate the effect of TCAs on AO pain. A recent study by Ito et al. [55] evaluated the effectiveness of milnacipran for pain relief in 36 patients with chronic pain in the orofacial region and a diagnosis of $\mathrm{AO}$ or burning mouth syndrome. They found that the visual analog scale score decreased significantly after treatment in comparison with the baseline score. To our knowledge, this is the only study to use milnacipran in the treatment of $\mathrm{AO}$, although the effectiveness of milnacipran on other pain disorders has been established [56-62]. High-quality clinical research such as a randomized controlled trial should be performed to assess the effectiveness of milnacipran in the treatment of AO.

\section{Are Anticonvulsants Effective for Treatment of AO?}

Anticonvulsants have been recommended for the management of $\mathrm{AO}$ and orofacial pain by several authors [63-65]. Recently, a systematic review on the effectiveness of anticonvulsants for the management of orofacial pain was conducted using randomized controlled trials [66]. According to this paper, gabapentin [67], topical clonazepam [68], lamotrigine [69], and carbamazepine [70, 71] reduce the pain intensity significantly in patients with chronic masticatory myalgia, stomatodynia, refractory trigeminal neuralgia, and trigeminal neuralgia, respectively. There is, however, limited to moderate evidence supporting the efficacy of the anticonvulsants for treatment of patients with orofacial pain disorder. More randomized controlled trials were needed to confirm the effectiveness [66]. Although AO is a type of oral facial pain disorder, there is less evidence supporting their effectiveness for AO. According to a paper reviewed by Matwychuk [72], the anticonvulsants can be used as a treatment and diagnostic tool for trigeminal neuralgia, whereas antidepressants have been reported to show good results for atypical odontalgia. Anticonvulsants may be less effective for AO than antidepressants. Further investigation is needed to clarify this hypothesis. 


\section{Conclusion}

There is insufficient evidence-based data available to establish guidelines for the diagnosis and treatment of AO thus far. Several diagnostic criteria for $\mathrm{AO}$ have been proposed $[1,6,8$, $9,49]$. Common findings in the criteria are "Pain is described as a toothache" and "No radiographic or laboratory investigations demonstrate relevant abnormality." Many other findings are shown in the criteria, but may not be essential for diagnosis. The present clinical questions addressing prevalence, comorbid diseases, and the characteristics of the pain may be useful for the establishment of diagnostic criteria. Further investigations are needed to consolidate the evidence base.

Evidence-based data are also needed to establish guidelines for treatment and management of AO. Precise pathophysiological information about the underlying mechanisms involved in $\mathrm{AO}$ is needed to provide an effective strategy for treatment or management of AO. As mentioned above, the three main hypotheses about the pathophysiology of $\mathrm{AO}$ relate to whether the condition has a psychogenic, vascular or neuropathic derivation. Diagnostic criteria of defined neuropathic pain [73] and a treatment algorithm for neuropathic pain based on evidence-based research [74] are available. These criteria and the algorithm could be applied to $\mathrm{AO}$ patients whose pain can be attributed to neuropathic factors. Such patients may be identified by the fact that local anesthesia results in pain relief. Meier et al. [50] proposed that neuropathic mechanisms are the primary cause of $\mathrm{AO}$ pain, and that psychological disturbances are probably more a consequence than the cause of chronic pain. Recently, diagnostic criteria for persistent dentoalveolar pain disorder were proposed by International RDC-TMD Consortium [75]. These criteria may be adaptive for AO. Since there is a general consensus about the involvement of psychological problems as either a primary or secondary cause of $\mathrm{AO}$, patients cannot be treated as if the pain is of neuropathic origin only. The patient's psychogenic background should always be considered in the treatment and/or management of AO. In the present paper, we attempted to use the most reliable evidence-based data. Recently, Patient-Oriented Evidence that Matters (POEM) is emerging as a more significant approach than evidence-based data for use in clinical practice $[76,77]$. Given that in psychosomatic diseases, doctorcentered interventions, and close observation of the doctorpatient relationship are of particular importance [78], clinicians may need to treat AO patients using the POEM approach.

\section{References}

[1] Headache Classification Committee of the International Headache Society, "Classification and diagnostic criteria for headache disorders, cranial neuralgias and facial pain," Cephalalgia, vol. 8, 7, pp. 1-96, 1988.

[2] R. L. Campbell, K. W. Parks, and R. N. Dodds, "Chronic facial pain associated with endodontic therapy," Oral Surgery Oral Medicine and Oral Pathology, vol. 69, no. 3, pp. 287-290, 1990.
[3] C. Feinmann and T. Newton-John, "Psychiatric and psychological management considerations associated with nerve damage and neuropathic trigeminal pain," Journal of Orofacial Pain, vol. 18, no. 4, pp. 360-365, 2004.

[4] G. A. Kaspo, "Atypical odontalgia in the dental office," The Journal of the Michigan Dental Association, vol. 77, no. 5, pp. 34-36, 1995.

[5] T. List, G. Leijon, M. Helkimo, A. Öster, and P. Svensson, "Effect of local anesthesia on atypical odontalgia-a randomized controlled trial," Pain, vol. 122, no. 3, pp. 306-314, 2006.

[6] J. J. Marbach, "Is phantom tooth pain a deafferentation (neuropathic) syndrome? Part I: evidence derived from pathophysiology and treatment," Oral Surgery Oral Medicine and Oral Pathology, vol. 75, no. 1, pp. 95-105, 1993.

[7] J. J. Marbach, "Phantom tooth pain," Journal of Endodontics, vol. 4, no. 12, pp. 362-372, 1978.

[8] J. J. Marbach and K. G. Raphael, "Phantom tooth pain: a new look at an old dilemma," Pain Medicine, vol. 1, no. 1, pp. 6877, 2000.

[9] R. A. Pertes, D. R. Bailey, and A. S. Milone, "Atypical odontalgia- a nondental toothache," Journal of the New Jersey Dental Association, vol. 66, no. 1, pp. 29-33, 1995.

[10] E. R. Vickers, M. J. Cousins, S. Walker, and K. Chisholm, "Analysis of 50 patients with atypical odontalgia: a preliminary report on pharmacological procedures for diagnosis and treatment," Oral Surgery, Oral Medicine, Oral Pathology, Oral Radiology, and Endodontics, vol. 85, no. 1, pp. 24-32, 1998.

[11] A. Woda and P. Pionchon, "A unified concept of idiopathic orofacial pain: clinical features," Journal of Orofacial Pain, vol. 13, no. 2, pp. 172-184, 1999.

[12] S. Ram, A. Teruel, S. K. S. Kumar, and G. Clark, "Clinical characteristics and diagnosis of atypical odontalgia: implications for dentists," Journal of the American Dental Association, vol. 140, no. 2, pp. 223-228, 2009.

[13] L. Baad-Hansen, G. I. Juhl, T. S. Jensen, B. Brandsborg, and P. Svensson, "Differential effect of intravenous S-ketamine and fentanyl on atypical odontalgia and capsaicin-evoked pain," Pain, vol. 129, no. 1-2, pp. 46-54, 2007.

[14] J. J. Marbach, J. Hulbrock, C. Hohn, and A. G. Segal, "Incidence of phantom tooth pain: an atypical facial neuralgia," Oral Surgery Oral Medicine and Oral Pathology, vol. 53, no. 2, pp. 190-193, 1982.

[15] M. Melis, S. L. Lobo, C. Ceneviz et al., "Atypical odontalgia: a review of the literature," Headache, vol. 43, no. 10, pp. 10601074, 2003.

[16] D. R. Nixdorf, E. J. Moana-Filho, A. S. Law, L. A. McGuire, J. S. Hodges, and M. T. John, "Frequency of persistent tooth pain after root canal therapy: a systematic review and metaanalysis," Journal of Endodontics, vol. 36, no. 2, pp. 224-230, 2010.

[17] D. R. Nixdorf, E. J. Moana-Filho, A. S. Law, L. A. McGuire, J. S. Hodges, and M. T. John, "Frequency of nonodontogenic pain after endodontic therapy: a systematic review and metaanalysis," Journal of Endodontics, vol. 36, no. 9, pp. 1494-1498, 2010.

[18] N. Polycarpou, Y. L. Ng, D. Canavan, D. R. Moles, and K. Gulabivala, "Prevalence of persistent pain after endodontic treatment and factors affecting its occurrence in cases with complete radiographic healing," International Endodontic Journal, vol. 38, no. 3, pp. 169-178, 2005.

[19] R. E. Bates Jr. and C. M. Stewart, "Atypical odontalgia: phantom tooth pain," Oral Surgery Oral Medicine and Oral Pathology, vol. 72, no. 4, pp. 479-483, 1991. 
[20] R. Jacobs, C. H. Wu, K. Goossens et al., "A case-control study on the psychophysical and psychological characteristics of the phantom tooth phenomenon," Clinical Oral Investigations, vol. 6, no. 1, pp. 58-64, 2002.

[21] R. T. Rees and M. Harris, "Atypical odontalgia," British Journal of Oral Surgery, vol. 16, no. 3, pp. 212-218, 1979.

[22] L. Reik Jr., "Atypical odontalgia: a localized form of atypical facial pain," Headache, vol. 24, no. 4, pp. 222-224, 1984.

[23] R. F. Schnurr and R. I. Brooke, "Atypical odontalgia: update and comment on long-term follow-up," Oral Surgery Oral Medicine and Oral Pathology, vol. 73, no. 4, pp. 445-448, 1992.

[24] T. List, G. Leijon, and P. Svensson, "Somatosensory abnormalities in atypical odontalgia: a case-control study," Pain, vol. 139, no. 2, pp. 333-341, 2008.

[25] R. J. Gatchel, Y. B. Peng, M. L. Peters, P. N. Fuchs, and D. C. Turk, "The biopsychosocial approach to chronic pain: scientific advances and future directions," Psychological Bulletin, vol. 133, no. 4, pp. 581-624, 2007.

[26] T. List, G. Leijon, M. Helkimo, A. Öster, S. F. Dworkin, and P. Svensson, "Clinical findings and psychosocial factors in patients with atypical odontalgia: a case-control study," Journal of Orofacial Pain, vol. 21, no. 2, pp. 89-98, 2007.

[27] B. Blasberg and A. Chalmers, "Temporomandibular pain and dysfunction syndrome associated with generalized musculoskeletal pain: a retrospective study," Journal of Rheumatology, vol. 16, no. 19, pp. 87-90, 1989.

[28] C. Hagberg, "General musculoskeletal complaints in a group of patients with craniomandibular disorders (CMD). A case control study," Swedish Dental Journal, vol. 15, no. 4, pp. 179$185,1991$.

[29] J. C. Türp, C. J. Kowalski, N. O’Leary, and C. S. Stohler, "Pain maps from facial pain patients indicate a broad pain geography," Journal of Dental Research, vol. 77, no. 6, pp. 14651472, 1998.

[30] A. Woda, S. Tubert-Jeannin, D. Bouhassira et al., "Towards a new taxonomy of idiopathic orofacial pain," Pain, vol. 116, no. 3, pp. 396-406, 2005.

[31] B. S. Galer and M. P. Jensen, "Development and preliminary validation of a pain measure specific to neuropathic pain: the neuropathic pain scale," Neurology, vol. 48, no. 2, pp. 332-338, 1997.

[32] R. I. Brooke, "Atypical odontalgia. A report of twenty-two cases," Oral Surgery Oral Medicine and Oral Pathology, vol. 49, no. 3, pp. 196-199, 1980.

[33] J. J. Klausner, "Epidemiology of chronic facial pain: diagnostic usefulness in patient care," The Journal of the American Dental Association, vol. 125, no. 12, pp. 1604-1611, 1994.

[34] M. K. Kreisberg, "Atypical odontalgia: differential diagnosis and treatment," The Journal of the American Dental Association, vol. 104, no. 6, pp. 852-854, 1982.

[35] R. G. Lascelles, "Atypical facial pain and depression," British Journal of Psychiatry, vol. 112, no. 488, pp. 651-659, 1966.

[36] J. J. Marbach, "Is phantom tooth pain a deafferentation (neuropathic) syndrome? Part II: psychosocial considerations," Oral Surgery Oral Medicine and Oral Pathology, vol. 75, no. 2, pp. 225-232, 1993.

[37] J. J. Marbach, "Phantom tooth pain: differential diagnosis and treatment," The New York State Dental Journal, vol. 59, no. 10, pp. 28-33, 1993.

[38] N. Bogduk and H. Merskey, Classification of Chronic Pain: Descriptions of Chronic Pain Syndromes and Definitions of Pain Terms, IASP Press, Seattle, Wash, USA, 2nd edition, 1994.

[39] L. Pöllmann, "Determining factors of the phantom tooth," The New York State Dental Journal, vol. 59, no. 10, pp. 42-45, 1993.
[40] R. A. Remick, B. Blasberg, J. S. Barton, P. E. Campos, and J. E. Miles, "Ineffective dental and surgical treatment associated with atypical facial pain," Oral Surgery Oral Medicine and Oral Pathology, vol. 55, no. 4, pp. 355-358, 1983.

[41] R. I. Brooke and R. F. Schnurr, "Diagnosing and treating atypical odontalgia," Journal of the Massachusetts Dental Society, vol. 44, no. 1, pp. 30-32, 1995.

[42] L. Baad-Hansen, G. Leijon, P. Svensson, and T. List, "Comparison of clinical findings and psychosocial factors in patients with atypical odontalgia and temporomandibular disorders," Journal of Orofacial Pain, vol. 22, no. 1, pp. 7-14, 2008.

[43] M. Takenoshita, T. Sato, Y. Kato et al., "Psychiatric diagnoses in patients with burning mouth syndrome and atypical odontalgia referred from psychiatric to dental facilities," Journal of Neuropsychiatric Disease and Treatment, vol. 6, pp. 699-705, 2010.

[44] S. B. Graff-Radford, Orofacial Pain: Assessment and Management, IASP Press, Seattle, Wash, USA, 1999.

[45] R. I. Brooke and H. Merskey, "Is atypical odontalgia a psychological problem?” Oral Surgery Oral Medicine and Oral Pathology, vol. 77, no. 1, pp. 2-3, 1994.

[46] R. Dubner and M. Gold, "The neurobiology of pain," Proceedings of the National Academy of Sciences of the United States of America, vol. 96, no. 14, pp. 7627-7630, 1999.

[47] M. Grushka, J. B. Epstein, and M. Gorsky, "Burning mouth syndrome and other oral sensory disorders: a unifying hypothesis," Pain Research and Management, vol. 8, no. 3, pp. 133135, 2003.

[48] J. P. Okeson and The American Academy of Orofacial Pain, Orofacial Pain, Guidelines for Assessment, Diagnosis, and Management, Quintessence, Chicago, Ill, USA, 1991.

[49] S. B. Graff-Radford and W. K. Solberg, "Atypical odontalgia," Journal of Craniomandibular Disorders: Facial \& Oral Pain, vol. 6, no. 4, pp. 260-265, 1992.

[50] T. Meier, G. Wasner, M. Faust et al., "Efficacy of lidocaine patch $5 \%$ in the treatment of focal peripheral neuropathic pain syndromes: a randomized, double-blind, placebo-controlled study," Pain, vol. 106, no. 1-2, pp. 151-158, 2003.

[51] J. G. Zagury, E. Eliav, G. M. Heir et al., "Prolonged gingival cold allodynia: a novel finding in patients with atypical odontalgia," Oral Surgery, Oral Medicine, Oral Pathology, Oral Radiology and Endodontology, vol. 111, no. 3, pp. 312-319, 2011.

[52] D. A. Fishbain, R. B. Cutler, H. L. Rosomoff, and R. S. Rosomoff, "Do antidepressants have an analgesic effect in psychogenic pain and somatoform pain disorder? A metaanalysis," Psychosomatic Medicine, vol. 60, no. 4, pp. 503-509, 1998.

[53] J. J. Sherman, L. LeResche, K. H. Huggins, L. A. Mancl, J. C. Sage, and S. F. Dworkin, "The relationship of somatization and depression to experimental pain response in women with temporomandibular disorders," Psychosomatic Medicine, vol. 66, no. 6, pp. 852-860, 2004.

[54] P. Svensson and L. Arendt-Nielson, "Clinical and experimental aspects of temporomandibular disorders," Current Review of Pain, vol. 4, no. 2, pp. 158-165, 2000.

[55] M. Ito, H. Kimura, K. Yoshida, Y. Kimura, N. Ozaki, and K. Kurita, "Effectiveness of milnacipran for the treatment of chronic pain in the orofacial region," Clinical Neuropharmacology, vol. 33, no. 2, pp. 79-83, 2010.

[56] R. M. Gendreau, M. D. Thorn, J. F. Gendreau et al., "Efficacy of milnacipran in patients with fibromyalgia," Journal of Rheumatology, vol. 32, no. 10, pp. 1975-1985, 2005. 
[57] M. Ito, K. Yoshida, H. Kimura, N. Ozaki, and K. Kurita, "Successful treatment of trigeminal neuralgia with milnacipran," Clinical Neuropharmacology, vol. 30, no. 3, pp. 183-185, 2007.

[58] M. Kamata, H. Takahashi, S. Naito, and H. Higuchi, "Effectiveness of milnacipran for the treatment of chronic pain: a case series," Clinical Neuropharmacology, vol. 27, no. 5, pp. 208210, 2004.

[59] E. Shimamoto, N. Doi, H. Suwa, F. Shibui, K. Ishimaru, and N. Fukubayashi, "A case of postherpetic neuralgia improved by milnacipran," Japanese Journal of Clinical Psychopharmacology, vol. 5, pp. 197-200, 2002.

[60] A. Toyofuku, "Efficacy of milnacipran for glossodynia patients," International Journal of Psychiatry in Clinical Practice, vol. 7, no. 1, pp. 23-24, 2003.

[61] K. Utunomiya, T. Ukita, and S. Hirita, "One case of postherpetic neuralgia treated with milnacipran," Japanese Journal of Clinical Psychopharmacology, vol. 5, pp. 193-196, 2002.

[62] O. Vitton, M. Gendreau, J. Gendreau, J. Kranzler, and S. G. Rao, "A double-blind placebo-controlled trial of milnacipran in the treatment of fibromyalgia," Human Psychopharmacology, vol. 19, no. 1, pp. S27-S35, 2004.

[63] M. A. Saxen, "Myofascial pain syndrome: characteristics, diagnosis, and treatment," Journal of the Indian Dental Association, vol. 77, no. 3, pp. 9-12, 1998.

[64] E. R. Vickers and M. J. Cousins, "Neuropathic orofacial pain part 1-prevalence and pathophysiology," Australian Endodontic Journal, vol. 26, no. 1, pp. 19-26, 2000.

[65] E. R. Vickers and M. J. Cousins, "Neuropathic orofacial pain. Part 2-diagnostic procedures, treatment guidelines and case reports," Australian Endodontic Journal, vol. 26, no. 2, pp. 53 63, 2000.

[66] W. J. J. M. Martin and T. Forouzanfar, "The efficacy of anticonvulsants on orofacial pain: a systematic review," Oral Surgery, Oral Medicine, Oral Pathology, Oral Radiology and Endodontology, vol. 111, no. 5, pp. 627-633, 2011.

[67] P. Kimos, C. Biggs, J. Mah et al., "Analgesic action of gabapentin on chronic pain in the masticatory muscles: a randomized controlled trial," Pain, vol. 127, no. 1-2, pp. 151160, 2007.

[68] C. Gremeau-Richard, A. Woda, M. L. Navez et al., "Topical clonazepam in stomatodynia: a randomised placebocontrolled study," Pain, vol. 108, no. 1-2, pp. 51-57, 2004.

[69] J. M. Zakrzewska, Z. Chaudhry, T. J. Nurmikko, D. W. Patton, and E. L. Mullens, "Lamotrigine (Lamictal) in refractory trigeminal neuralgia: results from a double-blind placebo controlled crossover trial," Pain, vol. 73, no. 2, pp. 223-230, 1997.

[70] J. M. Killian and G. H. Fromm, "Carbamazepine in the treatment of neuralgia. Use of side effects," Archives of Neurology, vol. 19, no. 2, pp. 129-136, 1968.

[71] C. F. Nicol, "A four year double-blind study of tegretol in facial pain," Headache, vol. 9, no. 1, pp. 54-57, 1969.

[72] M. J. Matwychuk, "Diagnostic challenges of neuropathic tooth pain," Journal of the Canadian Dental Association, vol. 70, no. 8, pp. 542-546, 2004.

[73] H. Kehlet, T. S. Jensen, and C. J. Woolf, "Persistent postsurgical pain: risk factors and prevention," The Lancet, vol. 367, no. 9522, pp. 1618-1625, 2006.

[74] N. B. Finnerup, M. Otto, H. J. McQuay, T. S. Jensen, and S. H. Sindrup, "Algorithm for neuropathic pain treatment: an evidence based proposal," Pain, vol. 118, no. 3, pp. 289-305, 2005.

[75] D. R. Nixdorf, M. T. Drangsholt, D. A. Ettlin et al., "Classifying orofacial pains: a new proposal of taxonomy based on ontology," Journal of Oral Rehabilitation, vol. 39, no. 3, pp. 161-169, 2012.

[76] L. A. Assael, "POEMs (patient-oriented evidence that matters): the surgeon's poetry," Journal of Oral and Maxillofacial Surgery, vol. 67, no. 11, pp. 2321-2322, 2009.

[77] F. Chiappelli and O. S. Cajulis, "Transitioning toward evidence-based research in the health sciences for the XXI century," Evidence-Based Complementary and Alternative Medicine, vol. 5, no. 2, pp. 123-128, 2008.

[78] P. Henningsen, S. Zipfel, and W. Herzog, "Management of functional somatic syndromes,” The Lancet, vol. 369, no. 9565, pp. 946-955, 2007. 


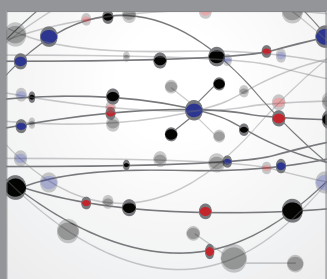

The Scientific World Journal
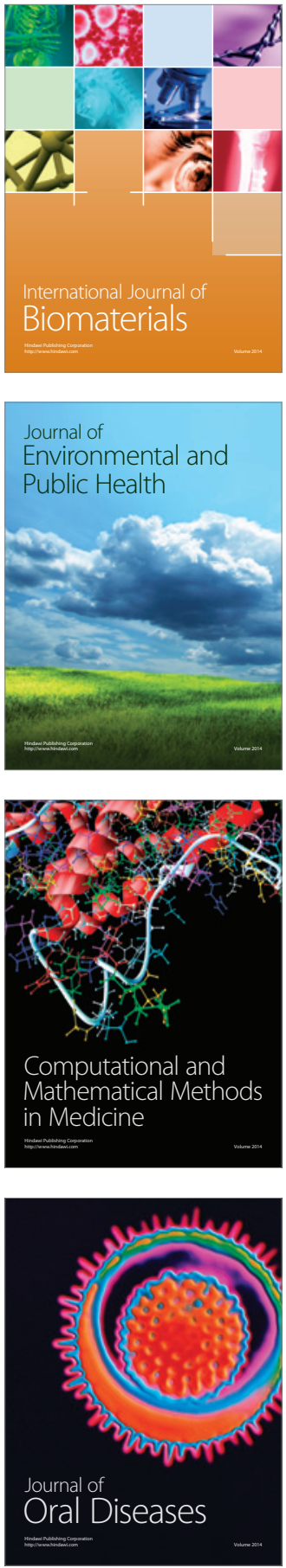
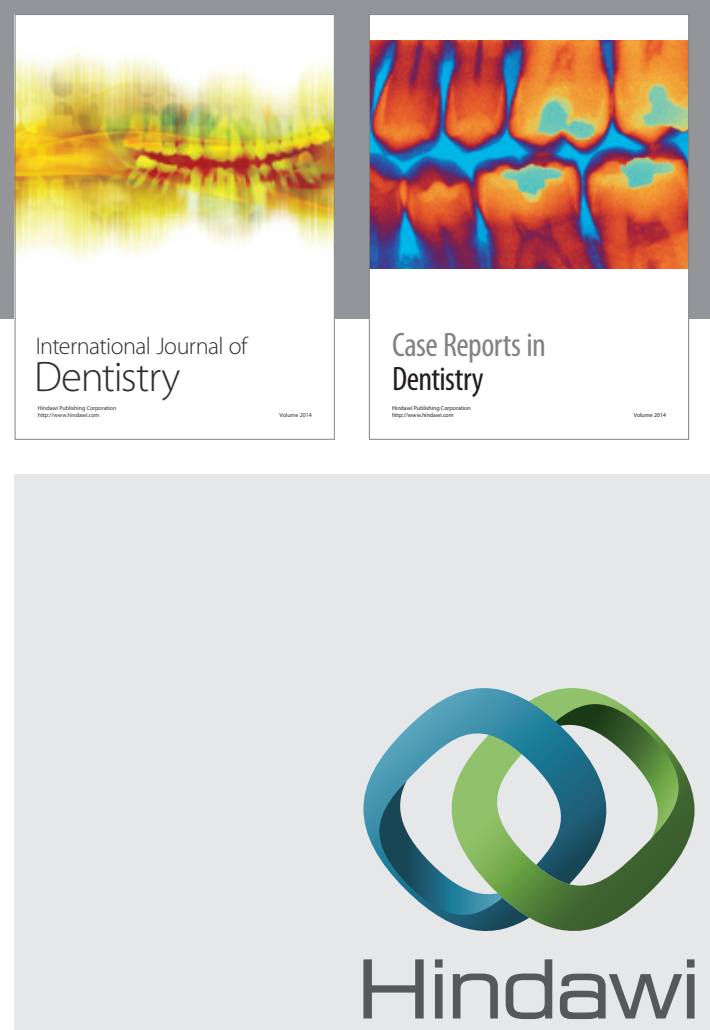

Submit your manuscripts at

http://www.hindawi.com
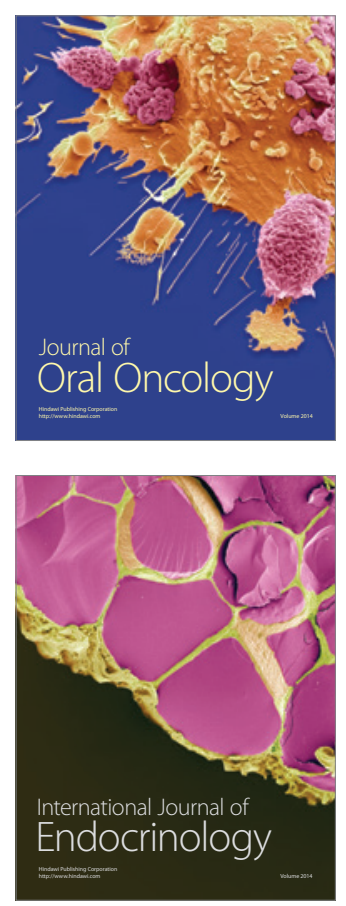
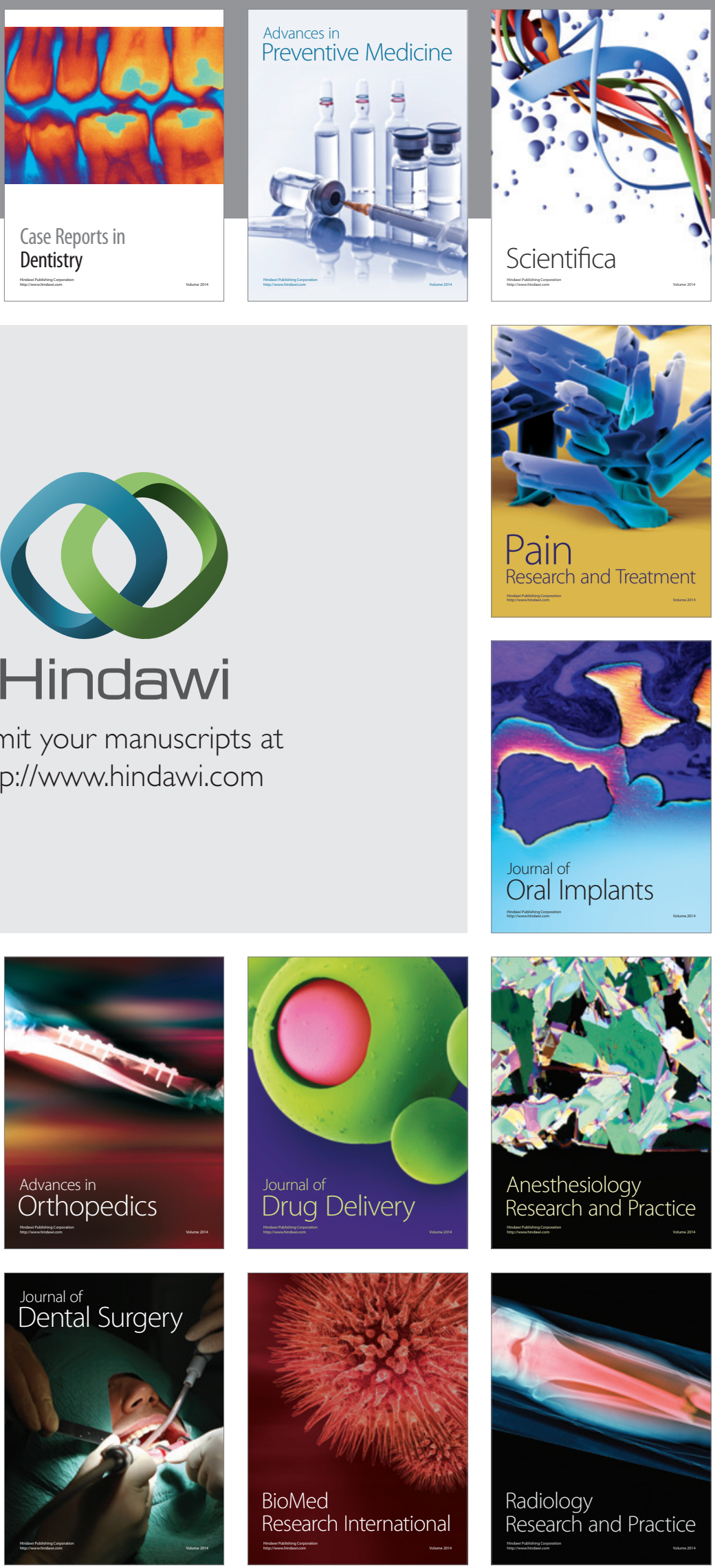